\title{
Potentiation of Fas-mediated apoptosis by attenuated production of mitochondria-derived reactive oxygen species
}

\author{
A Aronis ${ }^{1}, \mathrm{~J}$ Andr's Melendez ${ }^{2}, 0$ Golan $^{1}$, S Shilo ${ }^{1}, \mathrm{~N}$ Dicter ${ }^{1}$ \\ and 0 Tirosh $^{\star, 1}$ \\ 1 Institute of Biochemistry, Food Science and Nutrition, The Hebrew University \\ of Jerusalem, Rehovot 76100 , Israel \\ 2 Center for Immunology and Microbial Disease, Albany Medical College, \\ Albany, NY 12208, USA \\ * Corresponding author: 0 Tirosh, Institute of Biochemistry, Food Science and \\ Nutrition, The Hebrew University of Jerusalem, Rehovot 76100, Israel. \\ Tel: +1-972-8-9489623; Fax: +1-972-8-9476189; E-mail: otirosh@ agri.huji.ac.il
}

Received 17.6.02; revised 17.9.02; accepted 23.9.02

Edited by J. Tschopp

\begin{abstract}
The role of reactive oxygen species (ROS) production in death receptor-mediated apoptosis is ill-defined. Here, we show that ROS levels play a role in moderating Fas-dependent apoptosis. Treatment of Jurkat $T$ cells with oligomycin (ATP-synthase inhibitor) or (mitochondrial uncoupler) and Fas-activating antibody (CH11) facilitated rapid cell death that was not associated with decreased ATP production or increased DEVDase activity and cytochrome $c$ release. However, a decrease in cellular ROS production was associated with $\mathrm{CH} 11$ treatment, and combinations of CH11 with oligomycin or FCCP further inhibited cellular ROS production. Thus, decreased ROS production is correlated with enhanced cell death. A transition from state 3 to state 4 mitochondrial respiration accounted for the attenuated ROS production and membrane potential. Similar observations were demonstrated in isolated rat liver mitochondria. These data show that ROS production is important in receptor-mediated apoptosis, playing a pivotal role in cell survival.

Cell Death and Differentiation (2003) 10, 335-344. doi:10.1038/ sj.cdd. 4401150
\end{abstract}

Keywords: oxidants; signal transduction; cell death; mitochondria

Abbreviations: MPT, mitochondrial permeability transition; ROS, reactive oxygen species; MnSOD, manganese superoxide dismutase; $\mathrm{PI}$, propidium iodide; DCF, dichlorofluorescein; FCCP, carbonyl cyanide $p$-(trifluoromethoxy)phenyIhydrazone; TBH, $t$-butylhydroperoxide; FADD, fas-associated protein with death domain; $\mathrm{H}_{2} \mathrm{DCF}-\mathrm{DA}$, dichlorodihydrofluorescein-diacetate

\section{Introduction}

In addition to their critical function in energy metabolism, mitochondria are known to regulate cell viability as well as necrotic and apoptotic cell death. ${ }^{1-5}$ Four interrelated mitochondrial pathways have been suggested to facilitate cell death: (I) mitochondrial permeability transition (MPT) and the release of apoptotic cell death promoting factors; (II) cytochrome $c$ release by proapoptotic members of the BCL-2 family of proteins; ${ }^{6}$ (III) disruption of ATP production, and (IV) alteration of the cell's redox status and overproduction of reactive oxygen species (ROS). ${ }^{7-10}$

Two major apoptotic pathways are known: the death receptor pathway that responds to external triggering, such as cytokines, through caspase 8 activation, and the mitochondrial pathway that responds primarily to internal insults such as DNA damage, oxidative stress and kinase inhibitors. The two apoptotic pathways can be linked via the BCL-2 family member Bid protein, which upon cleavage by caspase 8 can interact with other family members to activate the mitochondrial apoptotic pathway. ${ }^{11-14}$

The contribution of the redox status of cells undergoing apoptosis is debatable and generally ill-defined. ROS are constantly produced in the living cell, and small changes in the redox status of cells can have profound effects on signal transduction pathways. ${ }^{15-17}$ Increased intracellular levels of ROS (oxidative stress) facilitate apoptosis, while further increases have been reported to oxidize elements of the apoptotic pathway and to promote necrotic cell death. ${ }^{18}$ However, during Fas-mediated apoptosis, enhancing the reducing environment using redox-active $\alpha$-lipoic acid can potentiate receptor-mediated apoptosis in Jurkat $\mathrm{T}$ cells. ${ }^{17}$ This suggests an important role for redox modulation in the regulation of receptor-mediated apoptotic cell death.

Mitochondria are considered to be the main source of ROS. ${ }^{19-21}$ Mitochondria from postmitotic cells use $\mathrm{O}_{2}$ at a high rate and may release oxygen radicals that exceed cellular antioxidant defenses. ${ }^{22}$ Indeed, mitochondria are the major source of superoxide anion production in cells. ${ }^{19,20}$ The electron-transfer chain may produce a flux of superoxide radicals via the one-electron reduction of molecular oxygen, which is then dismuted by manganese superoxide dismutase $(\mathrm{MnSOD})^{21}$ to produce a constant flux of hydrogen peroxide.

It is generally accepted that activation of Fas-mediated cell death is not responsive to inhibition by antioxidants. However, the present study indicates that ROS production can attenuate Fas-mediated apoptosis, and explains the inability of antioxidant strategies to inhibit cell death. Thus, by attenuating mitochondria-derived ROS fluxes, the rate of cell death can be intensified. 


\section{Results}

\section{Potentiation of Fas-mediated apoptosis in Jurkat T cells by the mitochondrial ATP synthase inhibitor oligomycin}

Activation of the Fas death domain pathway using the Fasactivating antibody $\mathrm{CH} 11$ resulted in cell death. Following $6 \mathrm{~h}$ of treatment with $\mathrm{CH} 11$, approximately $10 \%$ of the cells were

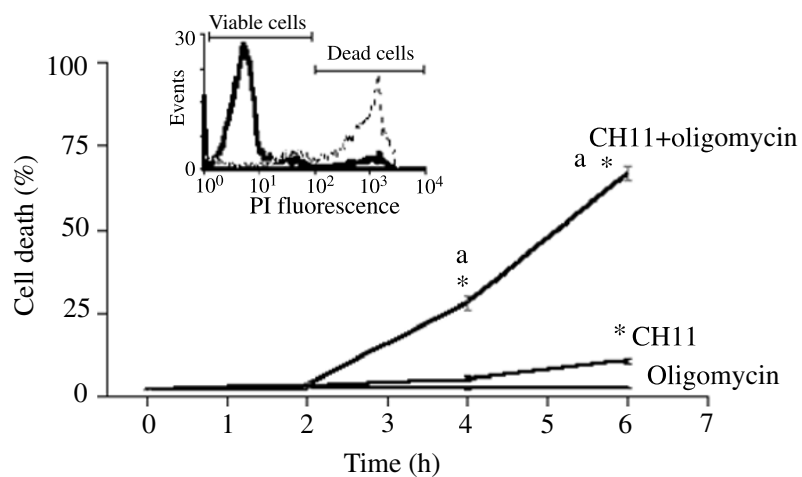

Figure 1 Potentiation of Fas-mediated cell death in Jurkat cells by oligomycin. $\mathrm{CH} 11(0.1 \mu \mathrm{g} / \mathrm{ml}$ million cells) was used as the Fas-activating antibody. Oligomycin $(10 \mu \mathrm{g} / \mathrm{ml})$ was added to the cell culture medium $5 \mathrm{~min}$ before $\mathrm{CH} 11$. " $P<0.05$, difference compared to beginning of treatment ( 0 time). ${ }^{a} P<0.05$, difference compared to $\mathrm{CH} 11$ alone at the time of treatment. Histograms: Representative flow cytometer histogram of cell viability following $6 \mathrm{~h}$ of treatments as indicated in the figure. Solid line, $\mathrm{CH} 11$; dashed line, $\mathrm{CH} 11+$ oligomycin

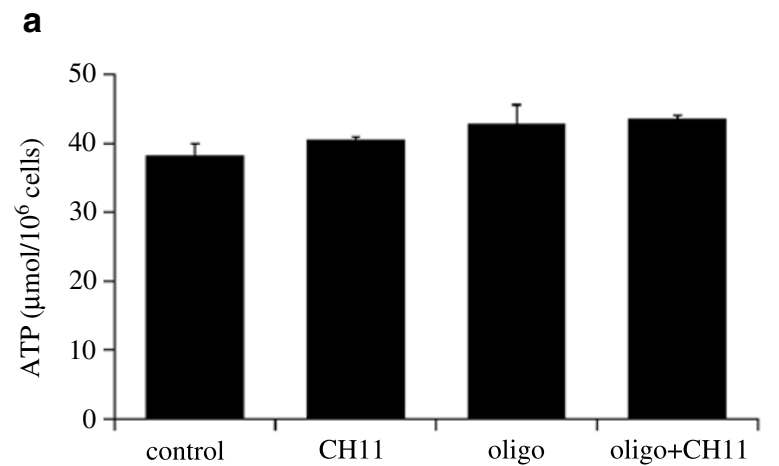

b

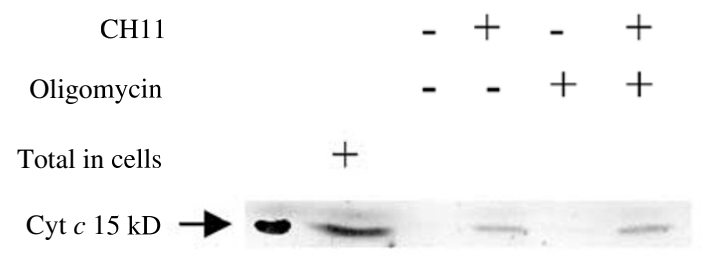

propoidium iodide $(\mathrm{PI})$ positive and considered dead cells (Figure 1). Addition of $10 \mu \mathrm{g} / \mathrm{ml}$ oligomycin did not facilitate cell killing in the Jurkat T-cell populations. However, a combination of oligomycin and $\mathrm{CH} 11$ facilitated rapid cell death of almost all cells in culture within the first $6 \mathrm{~h}$. Cell death began within $2 \mathrm{~h}$ of addition of the various apoptotic stimuli (Figure 1).

It has been reported that mitochondria can affect cell death by three interrelated mechanisms: (I) loss of the ability to generate ATP, leading to cell death; (II) mitochondrial release of proapoptotic factors such as cytochrome $c$ that activate caspase 9 to further activate downstream caspases and (III) redox-dependent alterations in mitochondria, promoting cell death. To determine which of these above pathways contribute to the synergistic increase in apoptosis, ATP levels, cytochrome $c$ release, caspase activation and ROS levels were evaluated in response to treatments with oligomycin, $\mathrm{CH} 11$ or their combination. HPLC analysis demonstrated no loss of ATP under any of the conditions that induced apoptosis (Figure 2a). $\mathrm{CH} 11$ treatment resulted in the release of cytochrome $c$ and strong activation of DEVDase activity (Figure 2b,c). However, no further augmentation in cytochrome $c$ release or DEVDase activity was recorded in cells that were treated with oligomycin $+\mathrm{CH} 11$ (Figure $2 b, c)$. Thus ATP depletion, increased mitochondrial cytochrome $c$ release or enhanced caspase activation could not account for the synergistic increase in apoptotic cell death following treatment with $\mathrm{CH} 11+$ oligomycin (Figure 2b,c). However, during Fas activation, it became clear that ROS production is attenuated by $\mathrm{CH} 11$. Treatments with oligomycin and $\mathrm{CH} 11$ further

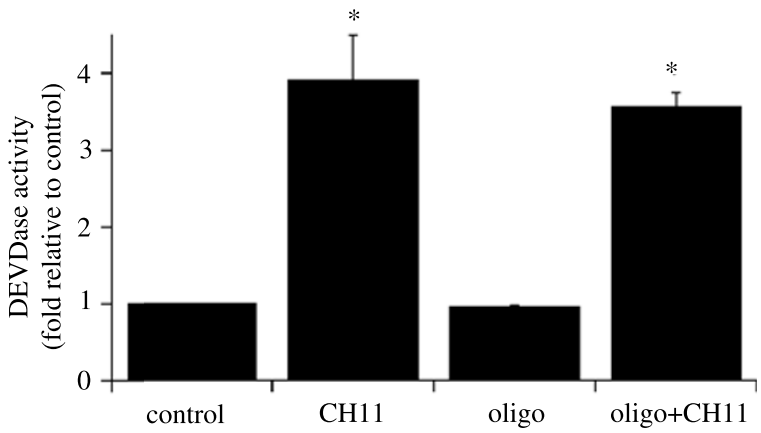

d

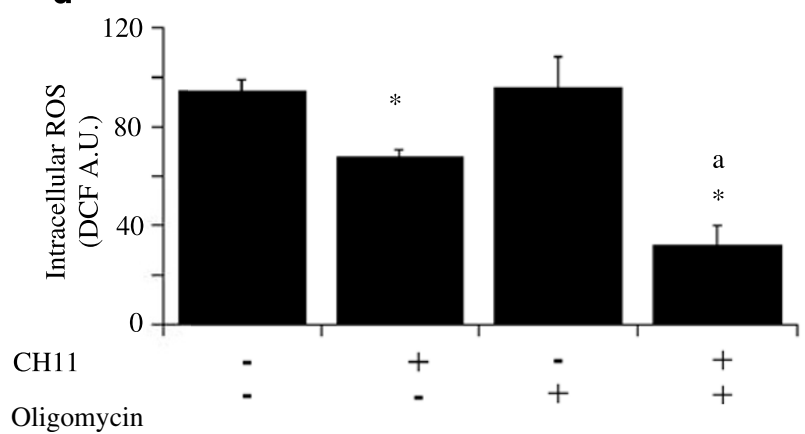

Figure 2 Early apoptotic events. Intracellular changes in apoptotic ( $\mathrm{CH} 11$ treated) Jurkat cells in the presence or absence of oligomycin. Measurements were made following $2 \mathrm{~h}$ of treatment, before the cells started dying: (a) cellular ATP levels, (b) cytochrome $c$ release from apoptotic cells, (c) DEVDase activity. ${ }^{*} P<0.05$, difference compared to control untreated cells, (d) intracellular ROS production measured by DCF fluorescence. ${ }^{*} P<0.05$, difference compared to control untreated cells. ${ }^{a} P<0.05$, difference compared to $\mathrm{CH} 11$-treated cells 
inhibited cellular ROS production (Figure 2d) and correlated with the increased rate of cell death (Figure 1). ROS production was decreased early in the death cascade and was observed before any significant cell death occurred (Figure 2d).

\section{Isolated mitochondria: oligomycin and state 4 respiration attenuate mitochondrial ROS production}

Isolated rat liver mitochondria in state 3 (ADP replete) respiration were treated with $1 \mu \mathrm{g} / \mathrm{ml}$ oligomycin, and ROS production was strongly inhibited, as evaluated using kinetic analysis of the ROS-sensitive fluorophore dichlorofluorescein diacetate (DCF) fluorescence (Figure 3a). In addition to the effect of oligomycin that blocks protons from going into the

a

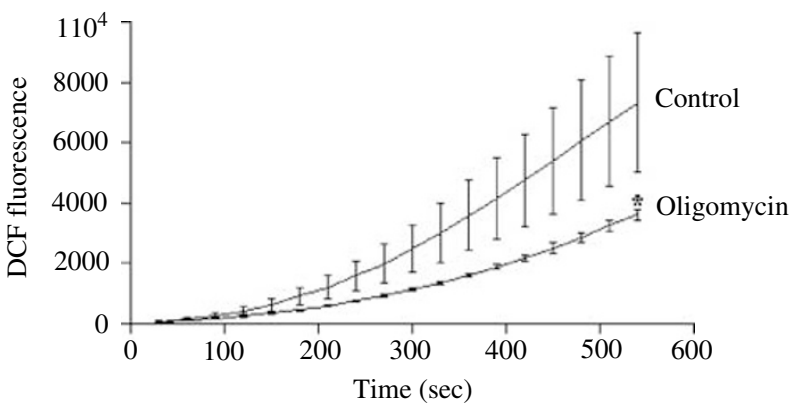

b

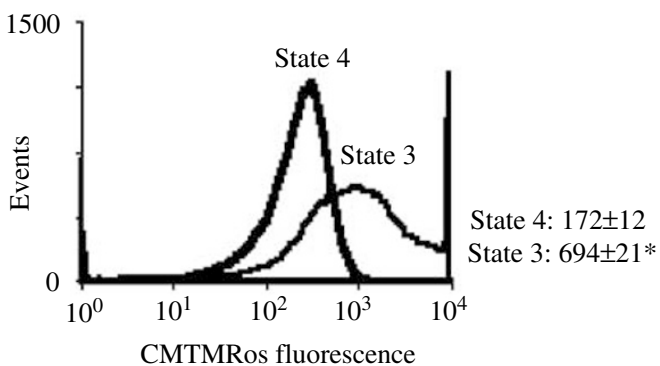

C

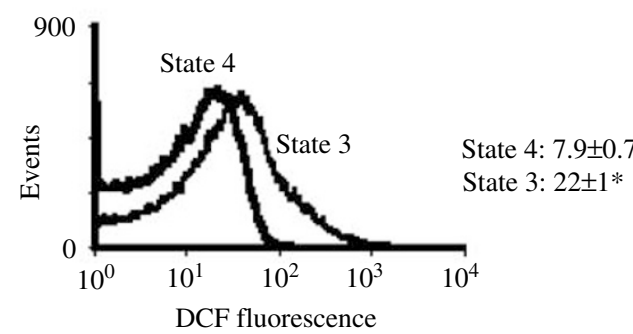

Figure 3 Inhibition of ROS production in isolated rat liver mitochondria by oligomycin. (a) Mitochondria in state 3 respiration were incubated with $1 \mu \mathrm{g} / \mathrm{ml}$ oligomycin, and DCF-sensitive ROS production was evaluated. Fluorescence data were collected by microfluorometer plate reader. ${ }^{\star} P<0.05$, difference compared to control untreated mitochondria. (b) Mitochondria in two different respiration states ( 3 and 4 ) were evaluated for membrane potential using CMTMRos and ROS production using DCF. Data from 50000 mitochondria were collected by flow cytometer. Histograms and total fluorescence (AU) data are presented. $P<0.05$, difference compared to state 4 mitochondria matrix, we suspected that there are basic differences in the capacity of isolated mitochondria to convert their superoxide to hydrogen peroxide during state 3 versus state 4 respiration. Mitochondria in state 3 showed an increase in ROSdependent DCF fluorescence and higher membrane potential than state 4 respiring mitochondria. The difference in membrane potential was nearly one order of magnitude (Figure $3 b)$, suggesting that a higher membrane potential is reached in order to maintain a balanced proton motive force to compensate for the decreased delta $\mathrm{pH}$ in the presence of ADP.

\section{Do Jurkat $T$ cells shift to state $\mathbf{4}$ mitochondrial respiration during apoptosis?}

Analysis of ADP levels demonstrated that they were approximately one-tenth of the ATP level (Figure 4). It is, therefore, likely that $A D P$ is the rate-limiting compound controlling mitochondrial respiration. Activation of the apoptotic process resulted in rapid consumption of cellular ADP within the first $4 \mathrm{~h}$ (Figure $4 \mathrm{a}$ ) and, thus, mitochondria in apoptotic cells were unable to sustain full state 3 respiration. The respiration shift was reflected by the observed loss of mitochondrial membrane potential in the apoptotic cells (Figure 4b). In digitonin-permeabilized cells, oligomycin and $\mathrm{CH} 11$ decreased ADP levels with an opposite effect on ATP (Figure 4c). Pellet-associated ADP levels were low, supporting the state 3 to state 4 respiration shift. This finding may explain why decreased membrane potential is observed without a requirement for mitochondrial permeability transition pore opening ${ }^{5}$ or increased mitochondrial oxidative damage during apoptosis. ${ }^{23}$

\section{Role of mitochondrial membrane potential in apoptosis}

Treatment of nonapoptotic Jurkat T cells with the mitochondrial uncoupler carbonyl cyanide $p$-(trifluoromethoxy)phenylhydrazone (FCCP) resulted in a rapid loss of the ability of mitochondria to produce ROS (Figure 5a). However, loss of cellular viability was not observed (not shown). Cellular ROS production was prolonged following $4 \mathrm{~h}$ of incubation with FCCP (Figure 5b). Cells treated with $\mathrm{CH} 11+\mathrm{FCCP}$ accelerated DNA fragmentation compared to treatment with either of them alone (Figure $5 \mathrm{c}$ ). Decreased mitochondrial membrane potential and ROS production were observed after $4 \mathrm{~h}$ of incubation (Figure $5 \mathrm{~d}, \mathrm{e}$ ). Cell death was also dramatically enhanced following prolonged $\mathrm{CH} 11+\mathrm{FCCP}$ treatment (Figure 5f). DEVDase activity was dependent on Fas activation by $\mathrm{CH} 11$. Such activity was also observed in the presence of FCCP (Figure $5 \mathrm{~g}$ ). These data indicate that the maintenance of a partial level of membrane potential is crucial for the generation of mitochondria-derived ROS during apoptosis.

\section{Type of cell death}

Using fluorescence microscopy, chromatin aggregation and nuclear fragmentation were documented following treatments with $\mathrm{CH} 11, \mathrm{CH} 11+$ oligomycin or $\mathrm{CH} 11+\mathrm{FCCP}$, indicating 
a

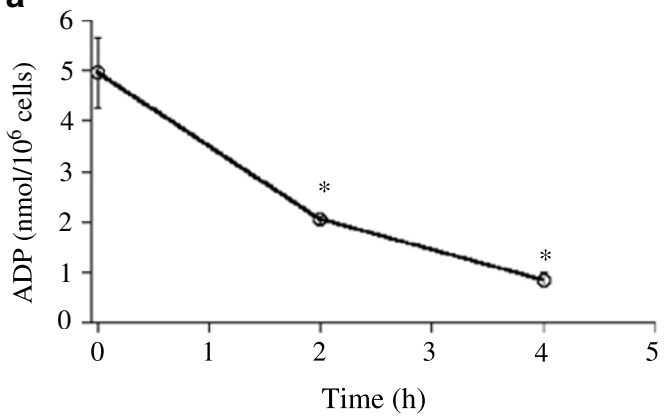

b

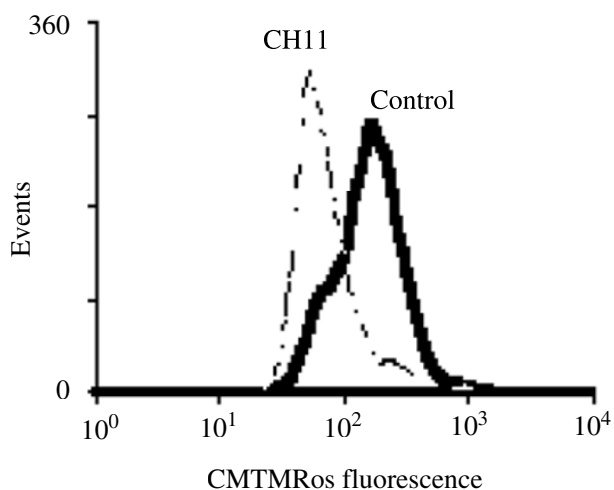

c
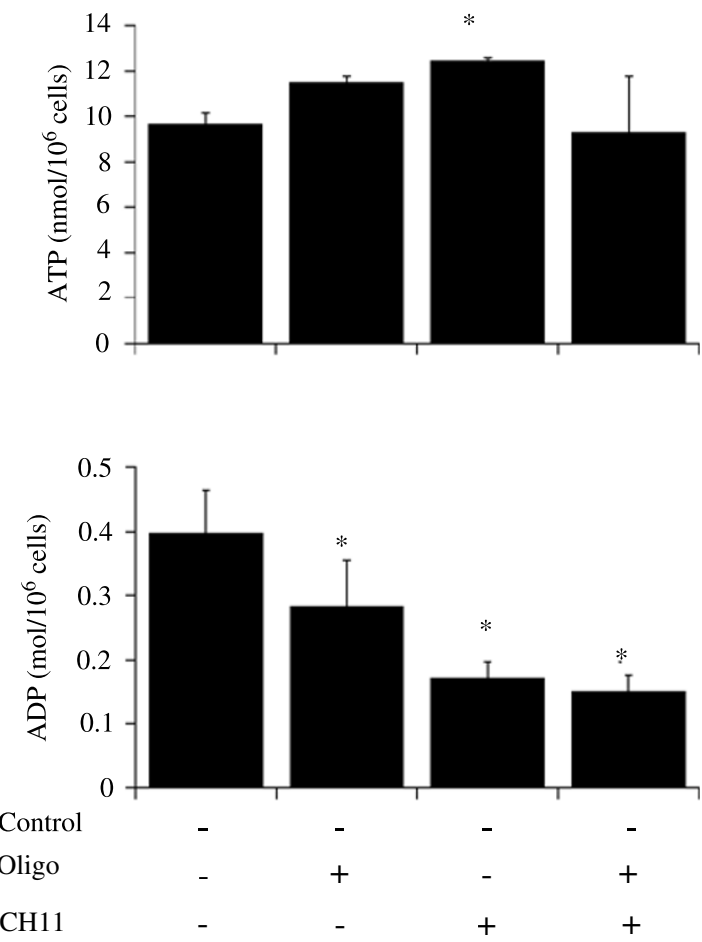

Figure 4. CH11 induces loss of ADP and mitochondrial membrane potential in Jurkat cells. (a) Treatment with $\mathrm{CH} 11$ for up to $4 \mathrm{~h}$ induced over $90 \%$ loss in cellular ADP content. ${ }^{*} P<0.05$, difference compared to untreated control. (b) Flow cytometer histogram demonstrating loss of mitochondrial membrane potential in apoptotic Jurkat cells. CMTMRos fluorescence reported loss in membrane potential that was observed in all cell populations following $4 \mathrm{~h}$ of exposure to $\mathrm{CH} 11$ (an early apoptotic event). Data were collected from 10000 cells. (c) Treatment with digitonin permeabilized the Jurkat cells, thereby allowing measurements which represent mitochondrial ATP/ ADP levels. Treatment with $\mathrm{CH} 11$ for up to $4 \mathrm{~h}$ induced over $60 \%$ loss in mitochondrial ADP content. $\mathrm{CH} 11$ significantly increased mitochondrial ATP. $P<0.05$, difference compared to untreated control

apoptotic characteristics of cell death (Figure 6). No apoptosis was observed in $\mathrm{CH} 11$ untreated cells.

\section{Cellular transfection with MSP-CAT plasmid}

A mitochondria-targeted catalase plasmid was transfected into Jurkat $\mathrm{T}$ cells and used to determine whether ROS are indeed important in the death process. Mitochondria-targeted catalase has previously been shown to potentiate apoptotic cell death in response to TNF and cycloheximide in HepG2 cells. ${ }^{24}$ Mitochondrial expression of catalase resulted in loss of the cells' ability to maintain normal levels of ROS (Figure $7 b)$ and resulted in enhanced cell death (Figure 7a). Addition of extracellular catalase to the incubation medium $(1000 \mathrm{U} / \mathrm{ml})$ did not result in enhanced cell death or a loss in the capacity to produce ROS (not shown).

\section{Can exogenous ROS provide protection?}

We used $t$-butylhydroperoxide (TBH) as an exogenous source of ROS. At $50 \mu \mathrm{M}, \mathrm{TBH}$ did not induce cell death in the time frame of the experiment (up to $6 \mathrm{~h}$ ). Addition of $\mathrm{TBH}$ resulted in elevated ROS in the control non-apoptotic cell population. The elevation of ROS affected all the cells in the culture (Figure 8a,b). Addition of $\mathrm{TBH}$ restored mean ROS levels in the apoptotic cells and elevated ROS production to that of nonapoptotic control cells. However, exogenous ROS did not fully compensate for the loss of endogenous mitochondria-derived ROS production observed in apoptotic cells (Figure 8b).

The ability of sublethal concentrations of $\mathrm{TBH}$ to protect against the lethal combination of $\mathrm{CH} 11$ and oligomycin was also tested. Protection by $\mathrm{TBH}$ was partial, and caspase activation (Figure 9a) was blocked by $\mathrm{TBH}$, as measured by DEVDase activity assay (performed under nonreducing conditions without DTT). In addition, nuclear protection was also observed (Figure 9b). TBH prevented DNA fragmentation but was unable to prevent the accumulation of $\mathrm{PI}$ in the apoptotic cells (Figure 9c).

\section{Discussion}

\section{Type of cell death}

Exposure of Jurkat T cells to the ATP synthase (complex 5) inhibitor oligomycin or the mitochondrial uncoupler FCCP potentiated the effect of $\mathrm{CH} 11$ Fas-activating antibody in facilitating cell death. In addition to apoptosis, Fas activation was reported previously to facilitate necrotic pathway of cell 
a

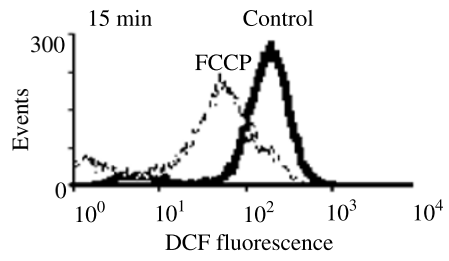

b

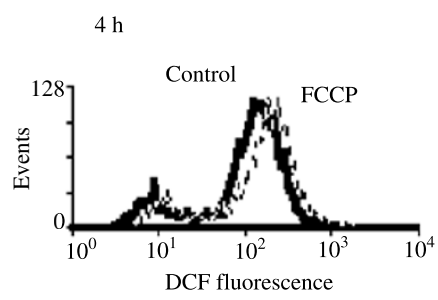

d

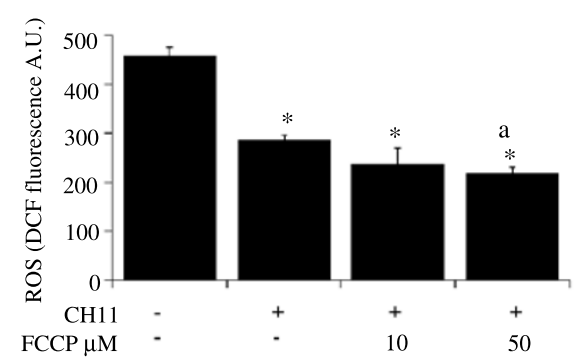

e

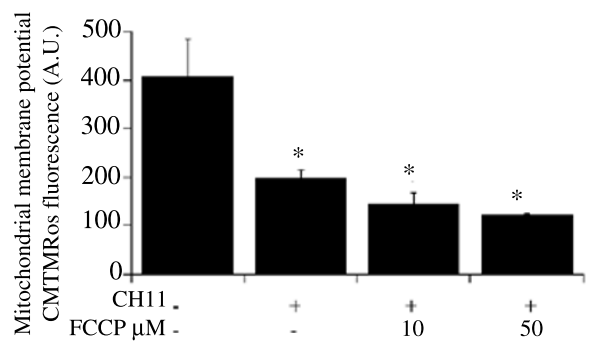

f

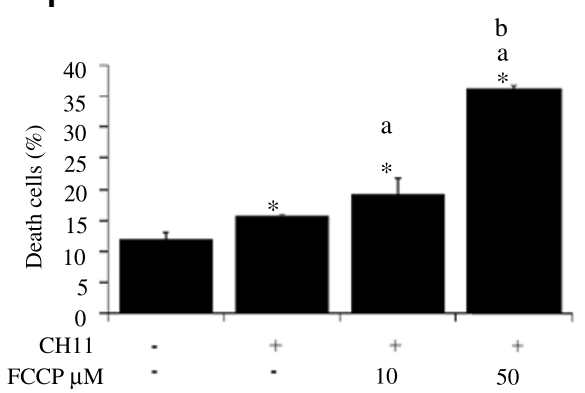

g

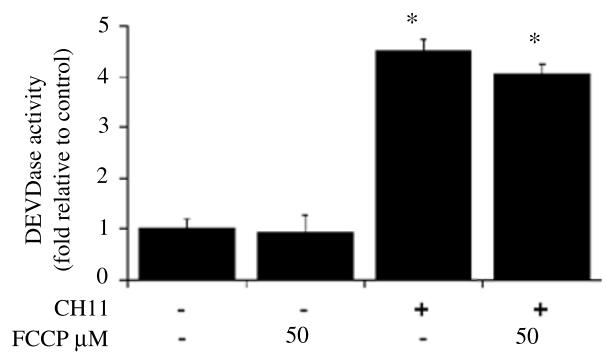

C

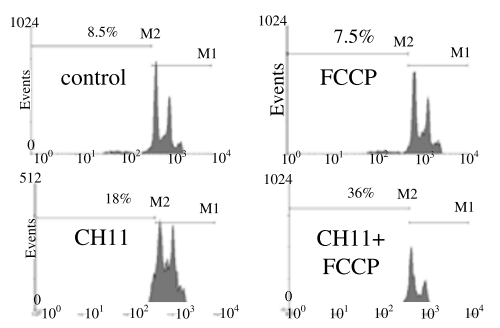

Figure 5 FCCP potentiates cell death and attenuates ROS production and mitochondrial membrane potential in apoptotic Jurkat cells. Cells were treated with FCCP. (a) Treatment with FCCP alone for $15 \mathrm{~min}$ induced a reduction in mitochondria-derived ROS compared to untreated control, indicating that most of cellular ROS are derived from the mitochondria. (b) Treatment with FCCP for $4 \mathrm{~h}$ caused an increase in mitochondrial ROS production owing to adaptation (as compared to 15 min treatment) as a result of compensation mechanism of the cell. (c) Combination of $50 \mu \mathrm{M} \mathrm{FCCP}+\mathrm{CH} 11$ exacerbated apoptosis as evaluated by the level of DNA fragmentation in Jurkat cells. Treatment was for $4 \mathrm{~h}$. (d) ROS production was measured by flow cytometry using DCFH-DA. Four hour of treatment with $\mathrm{CH} 11$ and $\mathrm{CH} 11$ together with FCCP reduced ROS production compared to control. ${ }^{*} P<0.05$, difference compared to untreated control. ${ }^{a} P<0.05$, difference compared to $\mathrm{CH} 11$-treated cells. (e) Membrane potential was measured by flow cytometry using CMTMRos fluorescence as membrane potential sensitive probe. Reduction in membrane potential was observed in the cells treated with $\mathrm{CH} 11$ or $\mathrm{CH} 11$ together with FCCP for $4 \mathrm{~h}$. ${ }^{*} \mathrm{P}<0.05$, difference compared to untreated control. ${ }^{\mathrm{a}} \mathrm{P}<0.05$, difference compared to $\mathrm{CH} 11$-treated cells. $(\mathrm{f})$ Measurement of cell viability by flow cytometry using PI demonstrated increased death of the cells treated with $\mathrm{CH} 11$ or $\mathrm{CH} 11$ and FCCP. The increase in FCCP concentration caused an increase in cell death rate. ${ }^{\star} P<0.05$, difference compared to untreated control. ${ }^{a} P<0.05$, difference compared to $\mathrm{CH} 11$ treated cells. ${ }^{b} P<0.05$, difference compared to $\mathrm{CH} 11+\mathrm{FCCP}(10 \mu \mathrm{M})$ treated cells. (g) DEVDase activity in cells treated with FCCP and $\mathrm{CH} 11$ for $4 \mathrm{~h} .{ }^{*} \mathrm{P}<0.05$, difference compared to untreated control

killing in cells that do not express caspase 8 and do not activate caspase in response to oligomerization of Fasassociated protein with death domain (FADD) ${ }^{25}$ or in the absence of active caspase. ${ }^{26}$ In the present study, DEVDase activity and chromatin aggregation were not compromised by oligomycin/ $\mathrm{CH} 11$ or $\mathrm{FCCP} / \mathrm{CH} 11$ treatment indicating that apoptosis is occurring.

\section{Regulation of apoptosis by ATP and ADP levels}

Oligomycin has been reported to protect against BAX, staurosporine and UV-induced apoptosis but not against Fas. ${ }^{27-29}$ The increased rate of cell death observed in the present study following oligomycin treatment is unrelated to the cellular energetic status. No ATP depletion was observed at early time points when apoptosis was apparent. In fact, ATP levels increased in digitonin-permeabilized cells following treatment with $\mathrm{CH} 11$ or oligomycin. The reason why ATP was not consumed in the mitochondria of cells treated with oligomycin, $\mathrm{CH} 11$ or a combination of both is not fully understood. It is possible that mitochondrial ATP is preserved owing to decreased consumption and/or a decrease in proton motive force-dependent adenine nucleotide translocase matrix-ATP exchange with cytosolic-ADP.

\section{Redox regulation of apoptosis}

Direct measurement of ROS production indicated that $\mathrm{CH} 11$ significantly attenuates ROS production and that treatment 

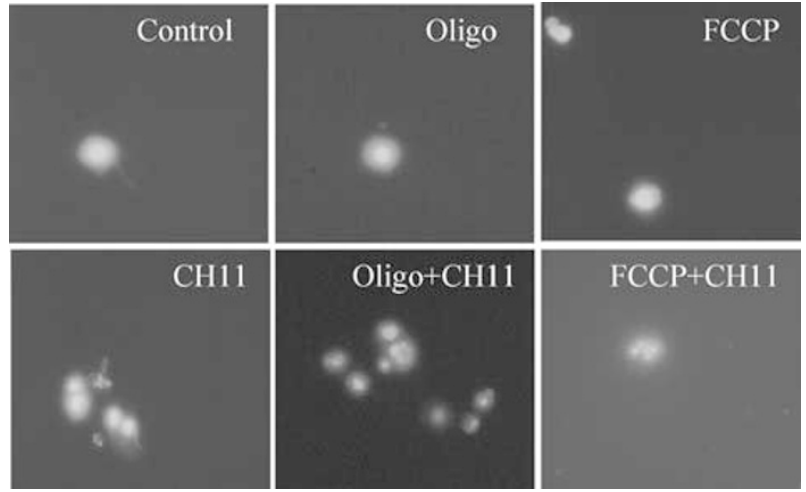

Figure 6 Visualization of chromatin changes in apoptotic cells. All treatments were for $4 \mathrm{~h}$. Cells were then fixed and permeabilized with $0.1 \%$ Triton-X-100 and stained with $\mathrm{PI}(10 \mu \mathrm{M})$. Pictures were taken at $\times 40$ magnification. Chromatin aggregation and fragmentation are characteristics of apoptotic cell death

\section{a}

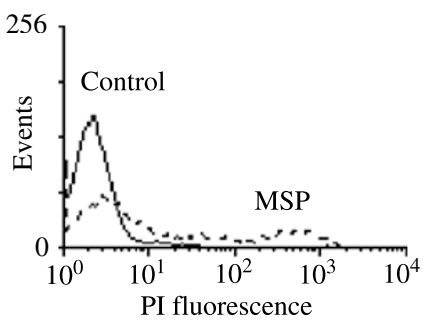

b

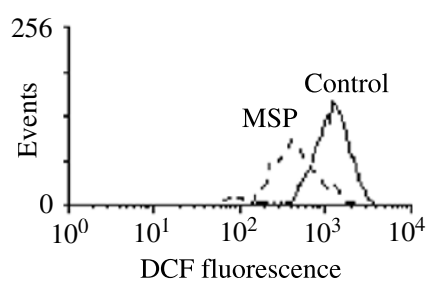

Control $=1007 \pm 170$

MSP $=500 \pm 250^{*}$

Figure 7 ROS production and cell viability in Jurkat T cells transfected with a catalase encoding plasmid. Jurkat T cells were transfected with pZeoSV/MSPCAT (MSP), a plasmid that encodes mitochondria-targeted catalase. (a) Flow cytometry histogram demonstrating cell viability measured using PI $48 \mathrm{~h}$ after transfection. Loss of cell viability as a result of nontransfection is observed compared to untransfected cells. Data were collected from 10000 cells. (b) Flow cytometry measurement of ROS production with the use of DCFH. Cells were gated or live cell population. Treatment resulted in the reduction of ROS production compared with untransfected cells. Data were collected from 10000 cells. Total fluorescence $(\mathrm{AU})$ data are presented. ${ }^{*} P<0.05$, difference compared to control

with oligomycin $+\mathrm{CH} 11$ further decreased mitochondria-derived ROS. The Fas (CD95) apoptotic pathway has not been shown to be associated with the production of ROS or the induction of oxidative stress. Furthermore, it has been reported that ROS inhibit Fas-induced cell death. The few studies indicating involvement of ROS in Fas-mediated apoptosis propose the use of SOD-mimicking compounds as protective agents. ${ }^{30}$ However, such compounds are not only antioxidants that remove superoxide anions, but that can

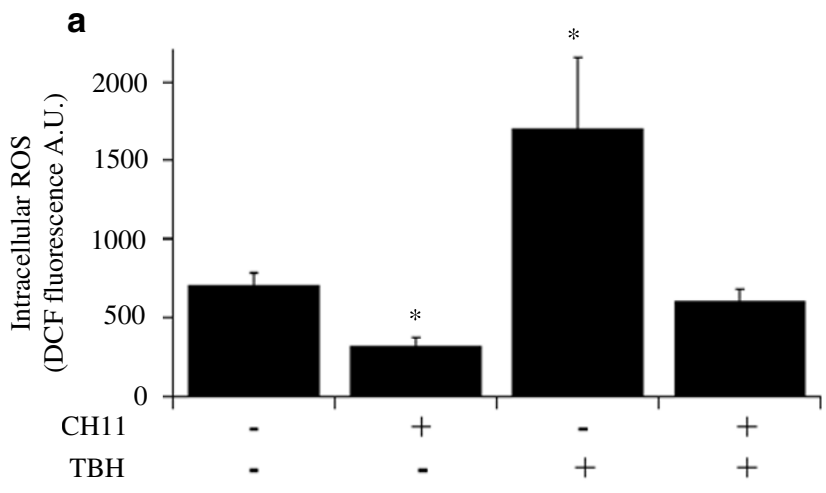

b

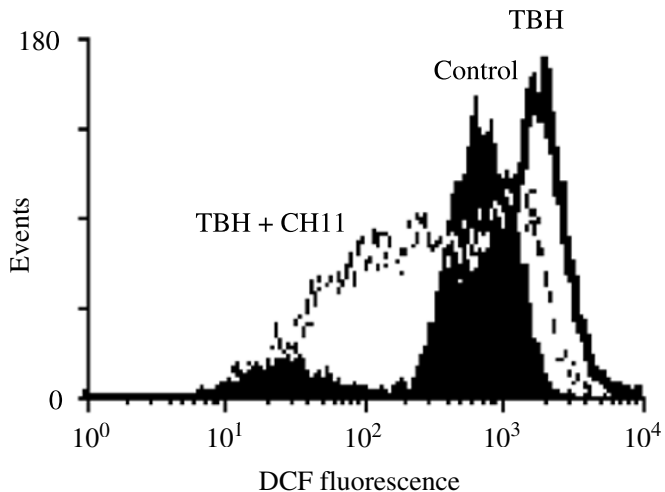

Figure 8 Distribution profile of exogenous ROS in apoptotic and nonapoptotic cells. (a) Fluorescence values collected by flow cytometer show that TBH was able to restore mean ROS levels in apoptotic cells compared to control untreated cells, but that level did not reach that of control TBH-treated cells. ${ }^{*} P<0.05$, difference compared to untreated control. (b) Histograms showing that exogenous ROS cannot compensate for the loss of endogenous ROS. Different profile of ROS distribution in apoptotic cells represented by low homogeneity compared to control cells

also serve as a source of $\mathrm{H}_{2} \mathrm{O}_{2}$. In fact, conventional antioxidants are virtually ineffective in controlling the death process. ${ }^{31}$ Moreover, long preincubation with lipoic acid, a thiol lipophilic antioxidant, can stimulate the Fas death pathway. ${ }^{17}$

It is widely held that cells possess strong redox buffering capacity to maintain viability. Increased oxidative stress will eventually lead to apoptosis and later on to necrotic cell death. ${ }^{18}$ Measurable levels of intracellular ROS are always produced in cells and also serve as signaling molecules for numerous signal transduction pathways. ${ }^{16}$ Tumor necrosis factor receptor-associated factor (TRAF)-mediated signal transduction facilitated ROS production from the mitochondrial electron-transfer chain resulting in enhanced NF-kB activation. ${ }^{32}$ Therefore, mitochondria-derived ROS may orchestrate the redox tone of the cell and thereby serve a function in cell survival. During Fas-mediated apoptosis, the capacity to produce ROS is impaired. The conversion of superoxide to hydrogen peroxide appears to be more dependent on the presence of protons in the matrix and therefore is oligomycin-sensitive. Such an effect is unique to apoptotic cells since oligomycin-dependent inhibition of ROS production was not observed in control cells. 
a

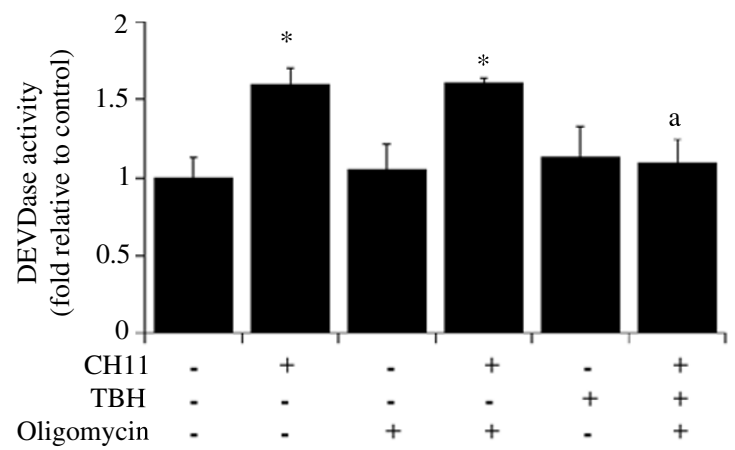

b

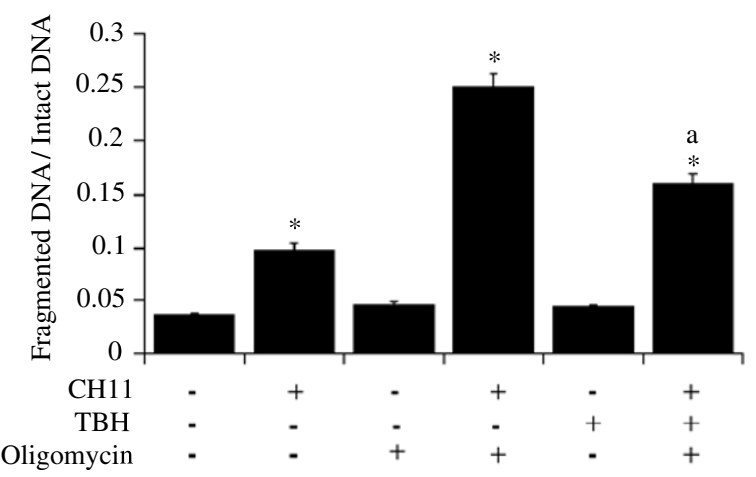

C

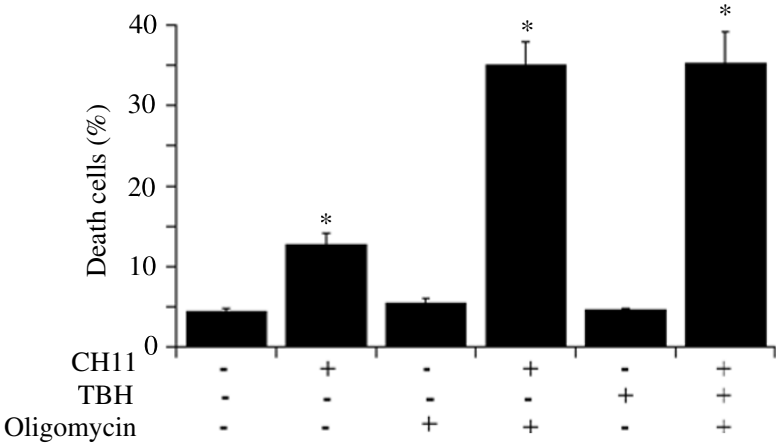

Figure 9 Effect of exogenous ROS: TBH $(50 \mu \mathrm{M})$ affects Jurkat T cells treated with $\mathrm{CH} 11$ and oligomycin. (a) Caspase-3-like activity: TBH prevented DEVDase activity in cells treated with $\mathrm{CH} 11+0$ ligomycin. DEVDase activity was measured under nonreducing conditions with no DTT. $P<0.05$, difference compared to untreated control. (b) Fragmented DNA: Level of DNA fragmentation measured by flow cytometry using PI to stain DNA was reduced by addition of TBH to cells treated with $\mathrm{CH} 11$ and oligomycin. ${ }^{*} P<0.05$, difference compared to untreated control. ${ }^{a} P<0.05$, difference compared to $\mathrm{CH} 11+$ oligomycin-treated cells. (c Membrane permeability: TBH was unable to protect cells treated with $\mathrm{CH} 11$ and oligomycin. Cell viability was measured by flow cytometry using PI. Data were collected from 10000 cells. ${ }^{*} P<0.05$, difference compared to untreated control

Treatment of isolated rat liver mitochondria during state 3 respiration attenuated DCF-sensitive ROS production (peroxides). The use of mitochondria in state 3 versus state 4 respiration revealed an attenuation of the mitochondrial membrane potential and ROS production. In apoptotic cells, rapid loss of membrane potential was also observed, accompanied by decreased ROS production. The proposal that ROS production is enhanced during state 4 respiration ${ }^{19}$ was not observed in the present study using isolated mitochondria. ROS production was directly correlated with, $\psi$ (state 4: no ATP, $\Delta \mathrm{pH}$ is maximal $\Delta \psi$ is minimal, state 3 is the opposite). Cellular ADP makes up approximately $10 \%$ of the ATP concentration. Therefore, intracellular degradation of ADP may shift cells from state 3 to state 4 respiration. This study indicates that an early event associated with cell death is ADP degradation. The respiration state could explain the observed loss of mitochondrial membrane potential in apoptosis via a mechanism that does not involve direct mitochondrial damage.

Superoxide has been suggested to serve as a natural inhibitor of Fas-mediated cell death. ${ }^{33}$ In contrast, SOD has also been shown to protect from apoptotic cell death, suggesting that superoxide facilitates and exacerbates this process. ${ }^{30}$ Elevated SOD levels have been shown to increase the intracellular production of $\mathrm{H}_{2} \mathrm{O}_{2}$ via its dismuting activity, and may explain the apoptosis inhibitory effects of both superoxide and SOD. ${ }^{15}$ In order to exclude the possibility that oligomycin shifts ROS production from hydrogen peroxide to superoxide, thereby enhancing cell death, apoptotic cells were treated with FCCP, a mitochondrial uncoupler. In agreement with our findings linking mitochondrial membrane potential and ROS production, FCCP attenuated ROS levels and enhanced cell death. Control cells were insensitive to the effect, most likely because of their ability to adapt and to rescue ROS production.

Transfection of Jurkat T cells with a plasmid that encodes a mitochondria-compartmentalized catalase also potentiated cell death. Mitochondrial catalase overexpression alone initiated cell death as a result of the inability to compensate for the loss of mitochondrial ROS (as measured in viable cells $48 \mathrm{~h}$ after transfection). $\mathrm{CH} 11$ did not further enhance apoptotic cell death in mitochondrial catalase overexpressing cell lines (data not shown). These data indicate that endogenous ROS levels are rate limiting in the process of receptor-mediated apoptotic cell death.

\section{Endogenous versus exogenous ROS}

Treatment of Jurkat T cells with TBH elevated total intracellular ROS in the cell population. The distribution of exogenous ROS affected the entire cell population. $\mathrm{TBH}$ treatment increased ROS levels in apoptotic cells. However, lack of homogeneity in the ROS levels in apoptotic cells following $\mathrm{TBH}$ treatment suggests that exogenous ROS cannot compensate fully for the loss of endogenous ROS production and only partially protects from apoptosis cell death.

In conclusion, we link the mitochondrial respiratory state to ROS production in apoptotic cells and establish that dissipation of intracellular ROS is an important step in facilitating Fas receptor-mediated cell death.

\section{Materials and Methods}

\section{Cell culture}

Human Jurkat T cells (ATCC) were grown in RPMI medium supplemented with $10 \%$ fetal calf serum, penicillin $(100 \mathrm{U} / \mathrm{ml})$ and streptomycin $(100 \mu \mathrm{g} /$ 
$\mathrm{ml}$ ) and $1 \times$ glutamine at $37^{\circ} \mathrm{C}$ in a humidified atmosphere consisting of $95 \%$ air and $5 \% \mathrm{CO}_{2}$. When cell density reached 1 million cells $/ \mathrm{ml}$, the cells were exposed to different apoptotic stimuli. $\mathrm{CH} 11$, a Fas-activating antibody, at a concentration of $0.1 \mu \mathrm{g} / \mathrm{ml}$ was used to initiate the receptor death domain dependent apoptotic process.

\section{Determination of cell viability}

Cell membrane integrity was detected by flow cytometry (FACSort, BD) as a measurement of cell viability. For this assay, the nonpermeant DNA interchelating dye $\mathrm{PI}$ that is excluded by viable cells was used. Fluorescence setting was excitation at $488 \mathrm{~nm}$ and emission at $575 \mathrm{~nm} .{ }^{17,34}$

\section{DNA integrity}

Cells exposed to apoptotic stimuli were centrifuged $(600 \times g, 5 \mathrm{~min})$ and collected. The pellet was resuspended in a solution containing $50 \mu \mathrm{g} / \mathrm{ml}$ $\mathrm{PI}, \quad 0.1 \%(\mathrm{w} / \mathrm{v})$ sodium citrate and $0.1 \%(\mathrm{v} / \mathrm{v})$ Triton-X-100. The permeabilized cells were kept in the dark for $2 \mathrm{~h}$ at $4{ }^{\circ} \mathrm{C}$ and their DNA integrity was analyzed using a flow cytometer. An argon-ion laser was used for excitation at $488 \mathrm{~nm}$ and the emission was recorded at $575 \mathrm{~nm}$. Data were collected from at least 10,000 cells. $^{7}$

\section{Caspase 3-like (DEVDase) activity}

Cell pellets were lysed in PBS containing $0.2 \%$ Triton X-100 on ice for $10 \mathrm{~min}$. The cell lysates were centrifuged at $10000 \times g$ for $5 \mathrm{~min}$. The clear supernatant was collected and placed on ice. Cell extracts $(50 \mu \mathrm{g} / \mathrm{ml}$ protein) were incubated with $60 \mu \mathrm{M}$ fluorogenic caspase-3 substrate (AcDEVD-AMC, Calbiochem, La Jolla, CA, USA) in incubation buffer (PBS) with or without $5 \mathrm{mM}$ dithiothreitol (DTT). Fluorescence was recorded following $30 \mathrm{~min}$ of incubation at ambient temperature in the dark using a microfluorometer plate reader (GENios, TECAN, AU), at $360 \mathrm{~nm}$ excitation and $460 \mathrm{~nm}$ emission. ${ }^{17}$

\section{Cytochrome $c$ released assay}

Mitochondrial intermembrane space release of cytochrome $c$ into the cytosol has been evaluated following induction of an apoptotic stimulus as described previously. ${ }^{35}$

\section{Digitonin-permeabilized cells}

Jurkat T cells $\left(10^{6} / \mathrm{ml}\right)$ were permeabilized with digitonin $(0.1 \% \mathrm{v} / \mathrm{v})$ in a medium that contained $100 \mathrm{mM} \mathrm{KCl}, 5 \mathrm{mM} \mathrm{KPi}, 5 \mathrm{mM}$ EDTA, $20 \mathrm{mM}$ HEPES, $1 \mu \mathrm{M}$ Rotenone and $1 \mu \mathrm{g} / \mathrm{ml}$ oligomycin. Permeabilized cells were centrifuged at $3000 \mathrm{rpm}$, washed and treated with acid for ATP/ADP extraction.

\section{Intracellular ATP and ADP}

Jurkat cells were washed with ice-cold PBS and treated with $4 \%(\mathrm{w} / \mathrm{v})$ phosphoric acid. All samples were immediately frozen in liquid nitrogen and stored at $-80^{\circ} \mathrm{C}$, until HPLC analysis. Immediately before the assay, samples were thawed, vortexed and then centrifuged at $15000 \times g$ for 5 min. The clear supernatant was removed and injected into the HPLC system. UV detection of intracellular ATP and ADP was performed using an ESA (Chelmsford, MA, USA) UV detector at $260 \mathrm{~nm}$ and a stationary phase of C-18 cyano (GL Science). The mobile phase consisted of phosphate buffer $\mathrm{pH} 2.7,50 \mathrm{mM}+4 \mathrm{mM}$ tetrabutylammonium hydrogen sulfate $95 \%$, and $5 \%$ methanol. The flow rate was $1 \mathrm{ml} / \mathrm{min}$.

\section{Intracellular ROS}

Intracellular ROS were detected using $\mathrm{H}_{2} \mathrm{DCF}-\mathrm{DA} .{ }^{7}$ After the different treatments, the cells were washed three times with PBS. Cells were centrifuged $(600 \times g, 5 \mathrm{~min})$ and resuspended in PBS and incubated with dichorodihydrofluoresceindia cetate $\left(\mathrm{H}_{2} \mathrm{DCF}-\mathrm{DA}\right)(25 \mu \mathrm{M})$ for $30 \mathrm{~min}$ at $37^{\circ} \mathrm{C}$. To detect intracellular fluorescence the fluorochrome-loaded cells were excited using a $488 \mathrm{~nm}$ argon-ion laser in a flow cytometer (FACSort, $B D)$. The dichlorofluorescein (DCF) emission was recorded at $530 \mathrm{~nm}$. Data were collected from at least 10000 cells.

\section{Isolation of rat liver mitochondria}

After overnight fasting, the animals were anesthetized and killed by decapitation. Livers were removed with scissors and immediately immersed in ice-cold $210 \mathrm{mM}$ mannitol, $70 \mathrm{mM}$ sucrose, $5 \mathrm{mM}$ HEPES, pH 7.35 (MSH buffer) containing $1 \mathrm{mM}$ EDTA. Livers were freed of fat and connective tissue, cut to pieces with scissors and homogenized in $60 \mathrm{ml}$ MSH/EDTA buffer per liver using a glass homogenizer with a Teflon pestle. Mitochondria were isolated by conventional differential centrifugation: ${ }^{36}$ The homogenate was centrifuged for $10 \mathrm{~min}$ at $1000 \times g$ at $4^{\circ} \mathrm{C}$ to sediment unbroken cells, cell debris and nuclei. The supernatant was centrifuged for $10 \mathrm{~min}$ at $10000 \times g$ at $4^{\circ} \mathrm{C}$ to give the first mitochondrial pellet. All manipulations of the mitochondria outside of the centrifuge were performed at $4{ }^{\circ} \mathrm{C}$. The fat layer floating on top of the supernatant was removed with a tissue and the supernatant was carefully decanted. The pellet was suspended in $80 \mathrm{ml}$ of MSH buffer per liver using a cold pestle and given another low spin $1000 \times g$ at $4^{\circ} \mathrm{C}$ for $5 \mathrm{~min}$. The supernatant was centrifuged for $10 \mathrm{~min}$ at $10000 \mathrm{rpm}$ at $4^{\circ} \mathrm{C}$, the pellet resuspended in $\mathrm{MSH}$ buffer and the last centrifugation step was repeated. The final mitochondrial pellet was suspended in about $1 \mathrm{ml}$ of MSH buffer to give a final concentration of $80-100 \mathrm{mg}$ mitochondrial protein $/ \mathrm{ml}$. Mitochondria were stored on ice and used within 3-6h after isolation. The protein content of the final mitochondrial suspension was determined by the Bradford method using bovine serum albumin as the standard.

\section{Standard incubation procedure}

Isolated mitochondria $(0.5-1 \mathrm{mg}$ protein $/ \mathrm{ml})$ were incubated at ambient temperature in a buffer consisting of $210 \mathrm{mM}$ mannitol, $70 \mathrm{mM}$ sucrose, $5 \mathrm{mM}$ HEPES, pH 7.4. Mitochondria were energized with $5 \mathrm{mM}$ succinate as the respiration substrate (state 4 respiration). For state 3 respiration, a different incubation medium was prepared as follows, $200 \mathrm{mM}$ sucrose, $20 \mathrm{mM}$ potassium chloride , $3 \mathrm{mM}$ potassium monophosphate, $5 \mathrm{mM}$ Tris base and $6 \mathrm{mM}$ magnesium chloride. ADP $80 \mu \mathrm{M}$ was used to initiate state 3 respiration in energized mitochondria.

\section{Mitochondrial ROS (hydrogen peroxide) measurements}

The electron-transfer chain may produce a flux of superoxide radicals via the one-electron reduction of molecular oxygen, which is then dismuted by $\mathrm{MnSOD}^{21}$ to produce a constant flux of hydrogen peroxide. Intramitochondrial peroxides were detected using $\mathrm{H}_{2} \mathrm{DCF}-\mathrm{DA}$. $^{37}$ The mitochondria were resuspended and incubated with $25 \mu \mathrm{M} \mathrm{H}_{2} \mathrm{DCF}-\mathrm{DA}$ for $10 \mathrm{~min}$ at room temperature for the detection of intramitochondrial fluorescence. The 
fluorochrome-loaded mitochondria were excited using a 488-nm argon-ion laser in a flow cytometer. DCF emission was recorded at $530 \mathrm{~nm}$. Data were collected from at least 50000 mitochondria.

\section{Determination of mitochondrial membrane potential}

Mitochondrial membrane potential was detected by flow cytometry. For this assay, the membrane potential sensitive fluorescent probe MitoTracker Orange CMTMRos was used at the following fluorescence settings: excitation at $488 \mathrm{~nm}$ and emission at $575 \mathrm{~nm}$ (FL2 channel). Isolated mitochondria ( $1 \mathrm{mg}$ ) were stained with $0.5 \mu \mathrm{M}$ CMTMRos, and samples were exposed to various treatments as described in the figure legends and analyzed for membrane potential. Under the experimental conditions used in this article, MitoTracker Orange CMTMRos did not induce any significant mitochondrial high-amplitude swelling (not shown). The probe was found to be highly sensitive to changes in the energy status of the mitochondria. ${ }^{37}$

\section{Evaluation of mitochondrial membrane potential in cells}

Jurkat T cells ( 1 million cells $/ \mathrm{ml}$ ) were stained with $0.1 \mu \mathrm{M}$ CMTMRos for $30 \mathrm{~min}$ at $37^{\circ} \mathrm{C}$. Accumulation of the dye in the mitochondria was evaluated by flow cytometer analysis as already described. Data were collected from 10000 cells.

\section{Micrographs pictures of the cells}

To determine the type of cell death (necrotic or apoptotic), control cells and cells treated with oligomycin or FCCP and $\mathrm{CH} 11$ alone or in combination were rinsed twice in PBS fixed with 1\% PFA for 30 min on ice and exposed to the DNA-binding fluorochrome $\mathrm{PI}(10 \mu \mathrm{M})$ dissolved in PBS containing $0.1 \%$ Triton-X-100. Emitted red fluorescence for $\mathrm{PI}$ was registered in a model U-VPT-P (Olympus Optical Co. Ltd., Japan) fluorescence microscope using a blue/green/red triple-pass filter. The results were documented using an optical camera.

\section{Cell transfection}

Before transfection, $10^{6}$ Jurkat $T$ cells were seeded. The expression plasmid vector pZeoSV2(+) containing human catalase cDNA with an MnSOD mitochondrial leader sequence (pZeoSV/MSP-CAT) as previosly described by Bai et $a I^{38}$ was transfected into Jurkat cells using the $X$ tremeGENE Q2 transfection reagent (Roche Diagnostics) according to the instructions provided by the manufacturer. Control cells and those exposed to $\mathrm{CH} 11$ treatment were analyzed for their capacity to generate ROS and for cell viability $48 \mathrm{~h}$ after transfection.

\section{Statistics}

Data are expressed as mean \pm S.D. of at least three experiments. Twoway ANOVA was used in multivariable analyses. Differences were considered significant at probability levels of $P<0.05$ using the Fisher's protected least significant difference method.

\section{Acknowledgments}

This research was funded by HU internal grant number 0346382 to OT and Public Health Service grant \#CA77068 to JAM.

\section{References}

1. Bernardi $P$, Petronilli V, Di Lisa F and Forte M (2001) A mitochondrial perspective on cell death. Trends Biochem. Sci. 26: 112-117

2. Green DR and Reed, JC (1998) Mitochondria and apoptosis. Science 281: 1309-1312

3. Kroemer G, Zamzami N and Susin SA (1997) Mitochondrial control of apoptosis. Immunol. Today 18: 44-51

4. Kroemer G and Reed JC (2000) Mitochondrial control of cell death. Nat. Med. 6: $513-519$

5. Reed JC (1997) Double identity for proteins of the Bcl-2 family. Nature 387 : $773-776$

6. Korsmeyer SJ et al. (2000) Pro-apoptotic cascade activates BID, which oligomerizes $\mathrm{BAK}$ or $\mathrm{BAX}$ into pores that result in the release of cytochrome $\mathrm{C}$. Cell Death Differ. 7: 1166-1173

7. Tirosh O, Sen CK, Roy S and Packer L (2000) Cellular and mitochondrial changes in glutamate-induced HT4 neuronal cell death. Neuroscience 97: 531541

8. Tan S, Sagara Y, Liu Y, Maher P and Schubert D (1998) The regulation of reactive oxygen species production during programmed cell death. J. Cell. Biol. 141, 1423-1432

9. Simon HU, Haj-Yehia A and Levi-Schaffer $F$ (2000) Role of reactive oxygen species (ROS) in apoptosis induction. Apoptosis 5, 415-418

10. Richter $C$ et al. (1995) Oxidants in mitochondria: from physiology to diseases. Biochim. Biophys. Acta. 1271: 67-74

11. Budihardjo I, Oliver H, Lutter M, Luo X and Wang X (1999) Biochemical pathways of caspase activation during apoptosis. Annu. Rev. Cell. Dev. Biol. 15: $269-290$

12. Luo X, Budihardjo I, Zou H, Slaughter C and Wang X (1998) Bid, a Bcl2 interacting protein, mediates cytochrome $c$ release from mitochondria in response to activation of cell surface death receptors. Cell 94: 481-490

13. Chou JJ, Li H, Salvesen GS, Yuan J and Wagner G (1999) Solution structure of $\mathrm{BID}$, an intracellular amplifier of apoptotic signaling. Cell 96: 615-624

14. Li H, Zhu H, Xu CJ and Yuan J (1998) Cleavage of BID by caspase 8 mediates the mitochondrial damage in the Fas pathway of apoptosis. Cell 94: 491-501

15. Ranganathan AC et al. (2001) Manganese superoxide dismutase signals matrix metalloproteinase expression via H2O2-dependent ERK1/2 activation. J. Biol. Chem. 276: 14264-14270

16. Sen CK (2000) Cellular thiols and redox-regulated signal transduction. Curr. Top Cell. Regul. 36: 1-30

17. Sen CK, Sashwati $R$ and Packer $L$ (1999) Fas mediated apoptosis of human Jurkat T-cells: intracellular events and potentiation by redox-active alpha-lipoic acid. Cell. Death Differ. 6: 481-491

18. Samali A, Nordgren H, Zhivotovsky B, Peterson E and Orrenius S (1999) A comparative study of apoptosis and necrosis in HepG2 cells: oxidant-induced caspase inactivation leads to necrosis. Biochem. Biophys. Res. Commun. 255: 6-11

19. Boveris A and Chance B (1973) The mitochondrial generation of hydrogen peroxide. General properties and effect of hyperbaric oxygen. Biochem. J. 134: 707-716

20. Chance B, Sies $H$ and Boveris A (1979) Hydroperoxides metabolism in mammalian organs. Physiol. Rev. 59: 527-605

21. Cadenas E and Davies KJ (2000) Mitochondrial free radical generation, oxidative stress, and aging. Free Radic. Biol. Med. 29: 222-230

22. Sastre J, Pallardo FV and Vina J (2000) Mitochondrial oxidative stress plays a key role in aging and apoptosis. IUBMB Life 49: 427-435

23. Petit PX et al. (1995) Alterations in mitochondrial structure and function are early events of dexamethasone-induced thymocyte apoptosis. J. Cell. Biol. 130: 157-167

24. Bai $\mathrm{J}$ and Cederbaum Al (2000) Overexpression of catalase in the mitochondrial or cytosolic compartment increases sensitivity of HepG2 cells 
to tumor necrosis factor-alpha-induced apoptosis. J. Biol. Chem. 275: 1924119249

25. Matsumura $\mathrm{H}$ et al. (2000) Necrotic death pathway in Fas receptor signaling. J. Cell. Biol. 151: 1247-1256

26. Holler $\mathrm{N}$ et al. (2000) Fas triggers an alternative, caspase-8-independent cell death pathway using the kinase RIP as effector molecule. Nat. Immunol. 1, 489-495

27. Matsuyama S, Llopis J, Deveraux QL, Tsien RY and Reed JC (2000) Changes in intramitochondrial and cytosolic $\mathrm{pH}$ : early events that modulate caspase activation during apoptosis. Nat. Cell. Biol. 2: 318-325

28. Vier J, Linsinger $G$ and Hacker $G$ (1999) Cytochrome $c$ is dispensable for Fasinduced caspase activation and apoptosis. Biochem. Biophys. Res Commun. 261: $71-78$

29. Eguchi Y, Srinivasan A, Tomaselli KJ, Shimizu S and Tsujimoto Y (1999) ATPdependent steps in apoptotic signal transduction. Cancer Res. 59: 2174-2181

30. Malassagne $B$ et al. (2001) The superoxide dismutase mimetic MnTBAP prevents Fas-induced acute liver failure in the mouse. Gastroenterology 121, 1451-1459

31. Alleva $R$ et al. (2001) Coenzyme $Q$ blocks biochemical but not receptormediated apoptosis by increasing mitochondrial antioxidant protection. FEBS Lett. 503: $46-50$
32. Chandel NS, Schumacker PT and Arch RH (2001) Reactive oxygen species are downstream products of TRAF-mediated signal transduction. J. Biol. Chem. 276: 42728-42736

33. Clement MV and Stamenkovic I (1996) Superoxide anion is a natural inhibitor of FAS-mediated cell death. EMBO J. 15: 216-225

34. Tirosh O, Guo Q, Sen CK and Packer L (2001) Mitochondrial control of inducible nitric oxide production in stimulated RAW 264.7 macrophages. Antioxid. Redox Signal 3: 711-719

35. Jung U, Zheng X, Yoon SO and Chung AS (2001) Se-methylselenocysteine induces apoptosis mediated by reactive oxygen species in $\mathrm{HL}-60$ cells. Free Radic. Biol. Med. 31: 479-489

36. Schweizer M and Richter C (1996) Peroxynitrite stimulates the pyridine nucleotide-linked $\mathrm{Ca} 2+$ release from intact rat liver mitochondria. Biochemistry. 35: 4524-4528

37. Aronis A, Komarnitsky R, Shilo S and Tirosh O (2002) Membrane depolarization of isolated rat liver mitochondria attenuates permeability transition pore opening and oxidant production. Antioxid. Redox Signal. 4(4): 647-654

38. Bai J, Rodriguez AM, Melendez JA and Cederbaum Al (1999) Overexpression of catalase in cytosolic or mitochondrial compartment protects HepG2 cells against oxidative injury. J. Biol. Chem. 274: 26217-26224 